뜸

\title{
La Alfombra Medieval del Museo Arqueológico y Etnológico de Granada. Acondicionamiento museográfico en la cripta del Palacio de Carlos V de La Alhambra
}

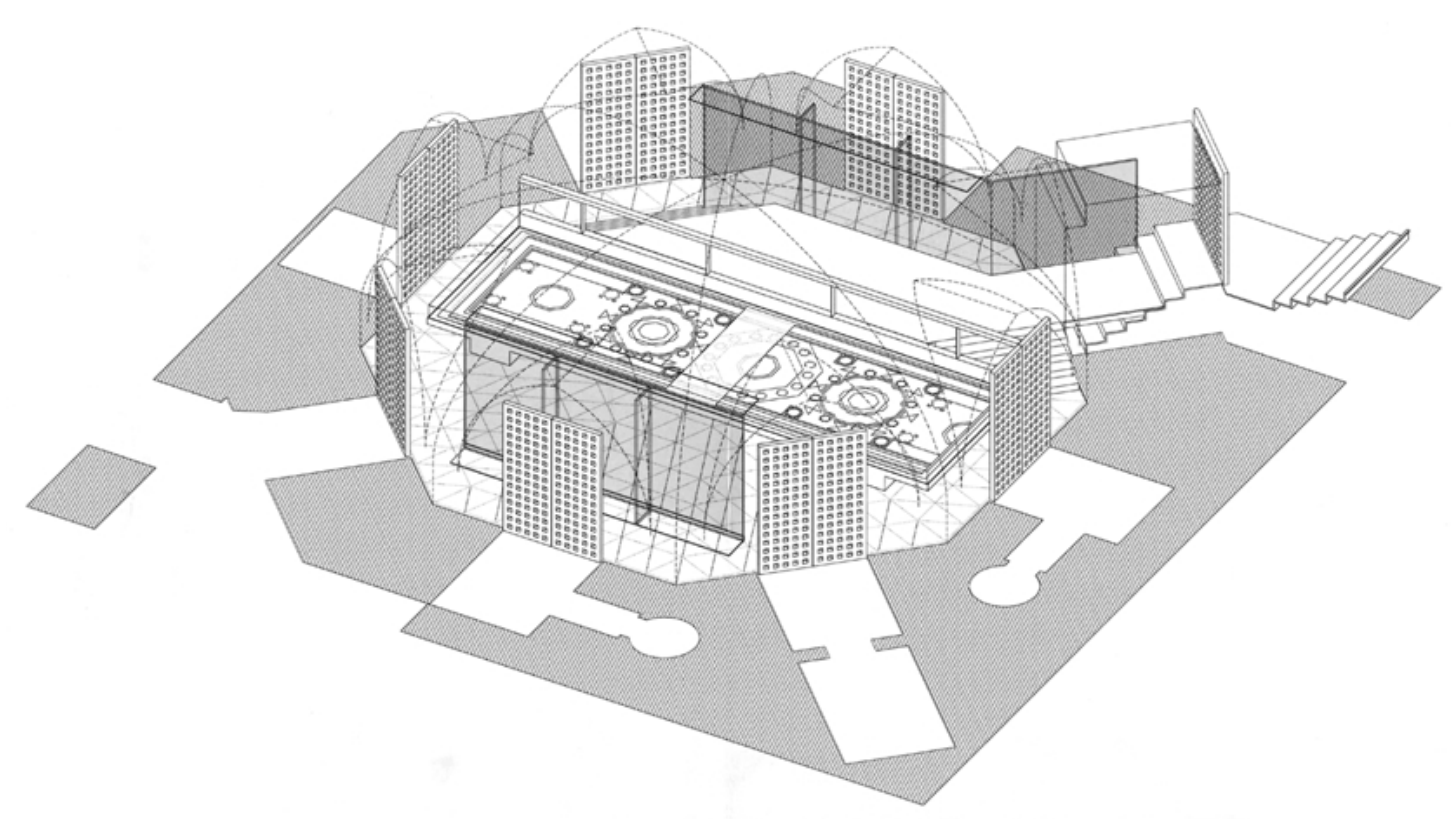

Antonio Tejedor Cabrera Mercedes Linares Gómez del Pulgar

Arquitectos

La alfombra medieval del Museo Arqueológico y Etnológico de Granada es una pieza excepcional, única en el mundo por su estilo y antigüedad. Procede posiblemente del conjunto de La Alhambra ya que pocas residencias aúlicas de la Granada nazarí disponían de salas capaces de albergar una alfombra de tal tamaño. En 1998 fue restaurada por el Instituto Andaluz del Patrimonio Histórico de la Consejería de Cultura, en colaboración con el Patronato de la Alhambra y Generalife.

El proyecto de acondicionamiento museográfico de la Cripta del Palacio de Carlos V para exposición permanente de la alfombra medieval persigue adecuar el espacio arquitectónico disponible a las necesidades de puesta en valor y conservación preventiva de esta pieza del siglo XV. Con la alfombra de estilo mameluco-nazarí se completan los extraordinarios contenidos del Museo de La Alhambra, ubicado en la planta baja del Palacio.

\section{La alfombra medieval}

A finales del siglo XIX D. Manuel Gómez Moreno compra varios fragmentos de la alfombra a la comunidad franciscana del convento del Ángel Custodio y deposita los dos mayores en el Museo Arqueológico y Etnológico de Granada. Al mismo tiempo, regala dos fragmentos más pequeños a los marqueses de Valencia de Don Juan para su colección de tejidos y otro, más pequeño, al museo de la Alhambra.

Tras una larga estancia de los dos fragmentos mayores en la Real Fábrica de Tapices de Madrid en los años setenta sin que se intervenga en ellos, en 1996 
ambos fragmentos fueron trasladados al I.A.P.H. donde se procedió a su análisis y posterior restauración.

La alfombra se puede describir técnicamente como un tejido de lana, de nudo persa, con una densidad de 850 nudos por $\mathrm{dm}^{2}$. Su decoración de estilo mameluco se compone de medallones, estrellas, lacerías y diminutos dibujos en colores blanco, azul, verde y amarillo sobre fondo rojo. Además presenta una franja ancha diseñada con cintas blancas de labor de lacería de ocho con fondo azul y los zafates de color verde. El primer fragmento mide 3,19 $\mathrm{m}$ de ancho por $4,55 \mathrm{~m}$ de largo; el segundo 3,16 por 4,42 m.

La intervención sobre las dos piezas se realizó, en función de las alteraciones de la obra, con un criterio puramente conservativo. Sin recurrir en ningún momento a reconstrucciones parciales, se emplearon materiales y tratamientos que se pueden resumir en líneas generales en las siguientes actuaciones (la memoria detallada de la restauración puede consultarse en: AA.VV. "Intervención y tratamiento de los dos fragmentos conservados de la denominada alfombra nazarî". En PH. Boletín del Instituto Andaluz del Patrimonio Histórico, $\left.n^{\circ} 23\right)$ :

- Eliminación de intervenciones anteriores.

- Eliminación de la cera natural de abeja que cubría toda la superficie.

- Limpieza en medio acuoso con detergente neutro.

- Secado, alineación de tramas y urdimbres y corrección de deformaciones.

- Consolidación local de lagunas con tejido de lino teñido en cada caso de color semejante al original y fijación con hilos de seda.

- Refuerzo y fijación de bordes.

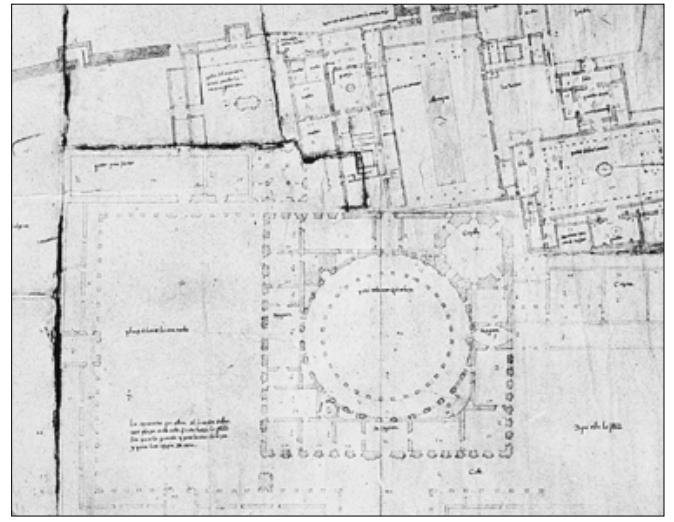

$\varangle$

山

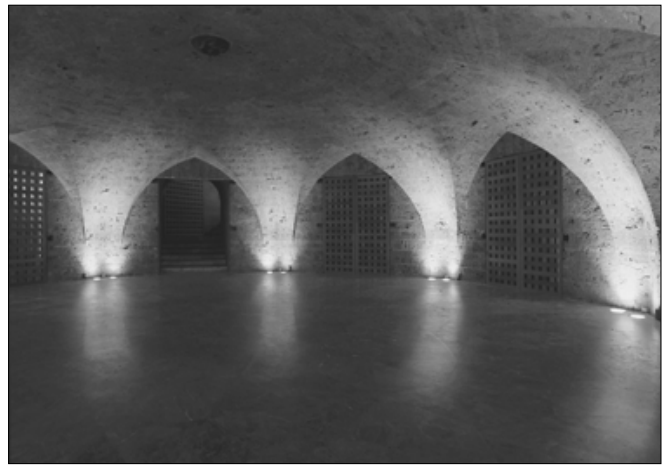

I. Planta Grande del Archivo General de Palacio donde se observa la posición de la capilla octogonal del Palacio de Carlos V.

2. Vista interior de la cripta del Palacio de Carlos V.

3. Los dos fragmentos de la alfombra medieval restaurados e hipótesis de restitución de la obra completa.

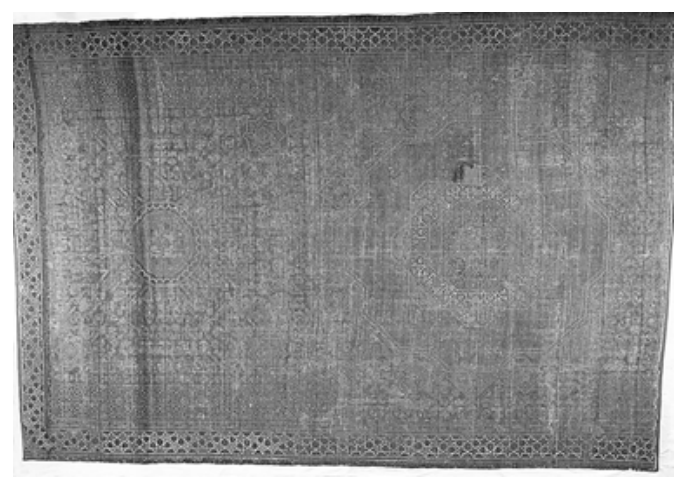

\section{El espacio de la cripta}

La cripta de la capilla del Palacio de Carlos V ha sido utilizada como sala de usos polivalentes (exposiciones temporales, actos, etc.) del Museo de la Alhambra que ocupa el ala sur del palacio. Situada en el vértice más próximo al Patio de los Leones, la sala es un espacio en
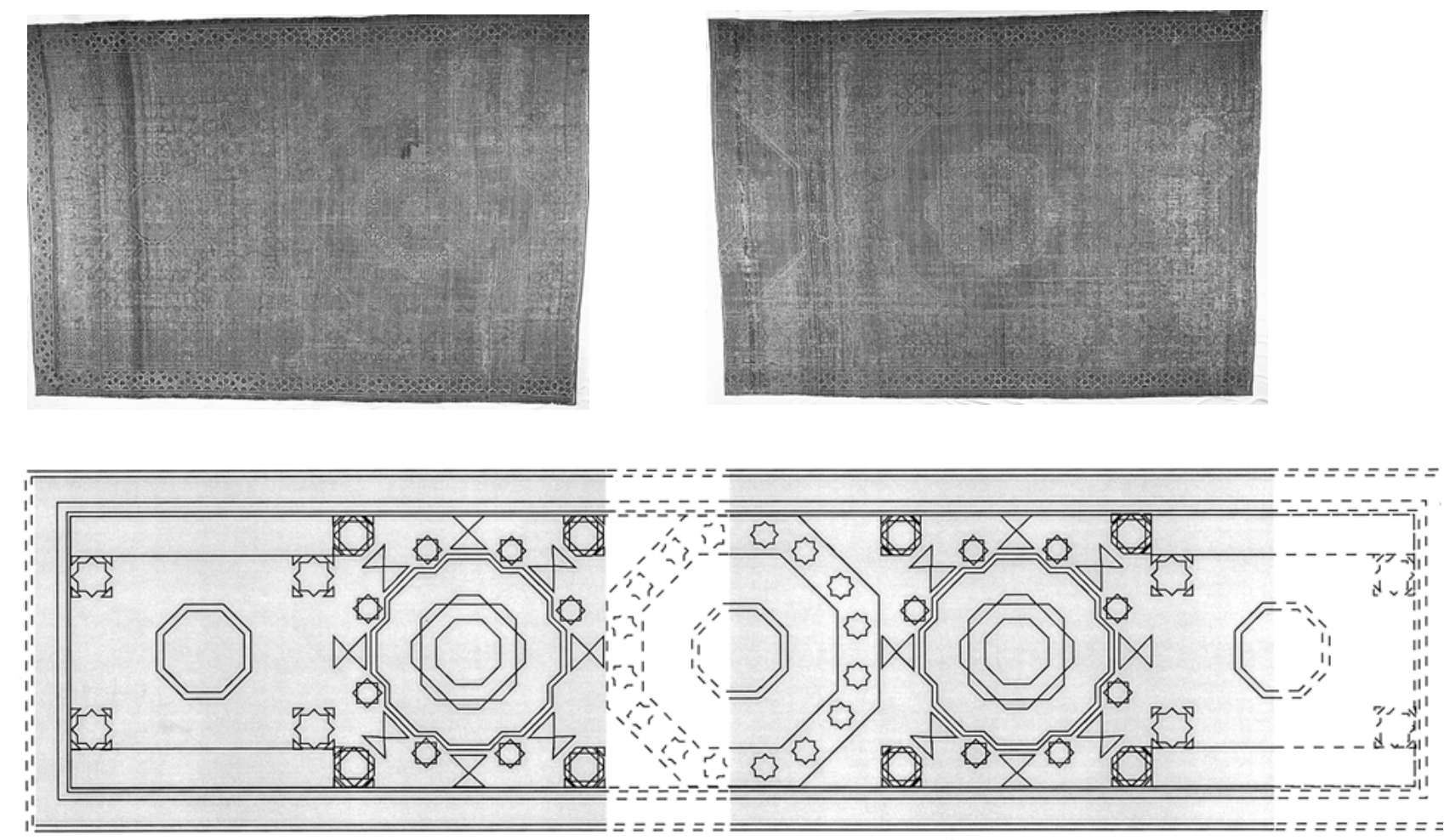


$\longleftarrow$
$\square$

semisótano de planta octogonal y cúpula rebajada también octogonal, con una circunferencia inscrita de 13,40 m de diámetro, que corresponde a una dimensión de 5,55 m de lado del octógono (casi $150 \mathrm{~m}^{2}$ de superficie). Los paramentos de la sala presentan aberturas idénticas que potencian la simetría múltiple de la cripta. Estos vanos corresponden a pequeñas salas rectangulares que perforan el gran espesor murario para

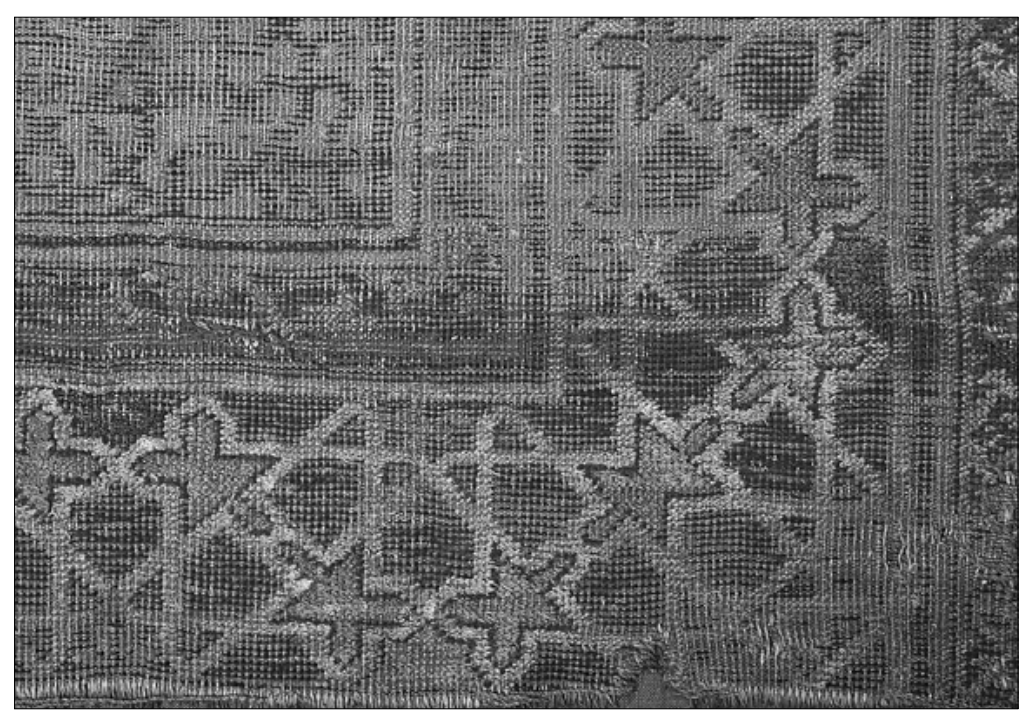

4. Detalle de la cenefa decorativa. Se pueden apreciar los colores verde y azul de los nudos sobre el fondo ocre-rojizo de la trama de base

5, 6. Vistas infográfícas de montaje expositivo. Primera propuesta
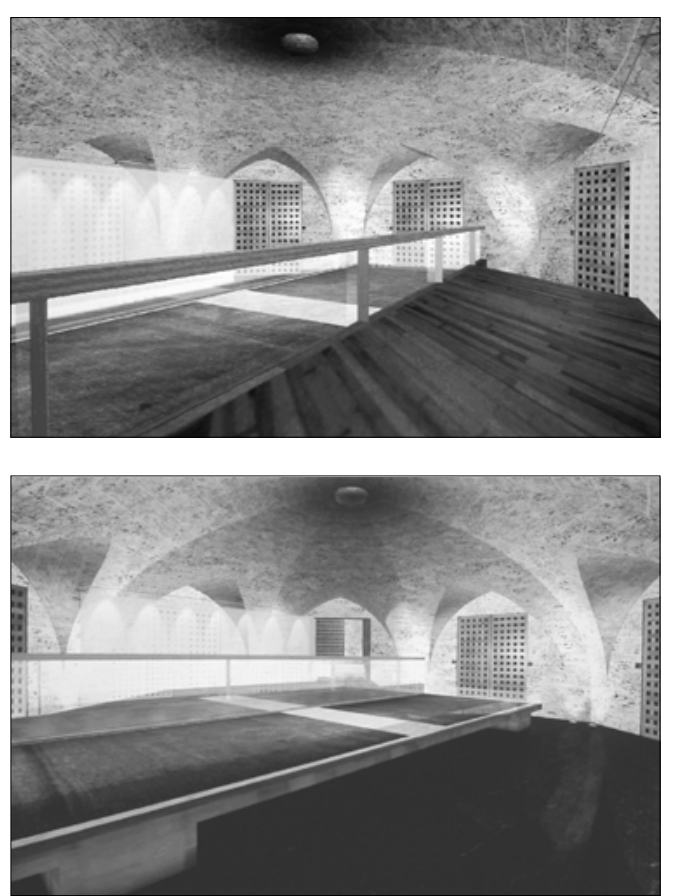

tomar luz del exterior a través de pequeñas ventanas en unos casos, o bien, para comunicar la cripta con el patio de Comares y con otros niveles del propio palacio. Una de estas pequeñas salas, la que se orienta hacia el centro del patio circular del palacio, es de mayor profundidad y se usa como almacén.

La sala destinada a acoger la alfombra está solada de mármol Val de Isoire despiezado en triángulos isósceles que conforman la planta octogonal. Las puertas de ma- dera de haya, idénticas en todos los vanos excepto en el de bajada a la cripta, que es de menor altura por la presencia de los escalones, son de gran potencia visual y refuerzan el peso específico de los planos de simetría en la percepción espacial. Por otro lado, la piedra de los paramentos presenta un tono homogéneo en toda la sillería.

La iluminación artificial disponible en la sala consiste en dieciséis luminarias ubicadas en el suelo que proyectan su luz bañando la bóveda por sus ocho aristas, proporcionando un grado de iluminación de 20 a 25 luxes en el plano de apoyo de la alfombra. Todas las instalaciones eléctricas discurren por el suelo que dispone además de calefacción por hilo radiante.

\section{El proyecto museográfico}

Es evidente que la disposición de los dos grandes fragmentos de la alfombra está supeditada al espacio disponible. Sin embargo, cabe hacer algunas consideraciones sobre las posibilidades manejadas en el proyecto.

A través del análisis de los dos fragmentos restaurados es posible deducir con bastante aproximación las dimensiones de la alfombra completa: 3,20 m de ancho por 1 1,40 m de largo. Es decir, las dimensiones máximas de la sala no permiten la completa restitución de la alfombra sin impedir el paso a su alrededor. Por esta razón, se optó por disponer las dos partes de la alfombra separadas, y mostrar en unos paneles informativos la hipótesis de restitución de la alfombra original. En función de la ubicación de estos paneles en el interior de la sala o en el exterior se elaboraron dos propuestas: en la primera dos paramentos de vidrio traslúcido acompañarían a la estructura-soporte de la alfombra y presentarían el estudio histórico-estilístico así como el proceso de restauración; en la segunda, se disponía un panel de menores dimensiones y contenidos más reducidos en el vestíbulo de acceso a la capilla, es decir, antes de entrar en la sala, alternativa por la que se optó finalmente.

El soporte de la pieza se concibe como una plataforma horizontal ligeramente sobreelevada del suelo y rodeada de una banda de vidrio. La plataforma de apoyo se dispone girada $45^{\circ}$ respecto del eje de acceso lo que permite la visión en diagonal de la alfombra al entrar en la sala.

En sintonía con las intervenciones realizadas en el Palacio de Carlos V para su adaptación parcial a Museo de la Alhambra, se ha realizado una intervención claramente diferenciada de las estructuras originales, con una fuerte intención de neutralidad formal que favorece la puesta en valor del objeto artístico. Se potencia el sentido de adición y superposición gracias a la autonomía de los elementos introducidos, simplemente apoyados sobre el suelo y sin contacto con los muros, lo cual lleva implícito a su vez un criterio de completa reversibilidad. La musealización del tejido nazarí se complementa con un panel informativo sobre el mismo y su proceso de restauración. 
Se han utilizado pocos materiales (madera de roble, vidrio y acero inoxidable), escasamente elaborados desde el punto de vista formal, pero bien construidos para reducir el mantenimiento al mínimo y garantizar las mejores condiciones de conservación de la obra.

\section{Consideraciones sobre conservación preventiva, materiales y acabados}

I. Radiaciones ultravioletas e infrarrojas

Se han dispuesto filtros de luz ultravioleta en los dos vanos en los que se ha sustituido la carpintería por ventanas de acero inoxidable. Se comprobarán las emisiones de radiaciones ultravioletas e infrarrojas de los proyectores de suelo existentes por si fuera necesaria una corrección de los mismos incorporando filtros especiales.

2. Niveles de humedad y temperatura

La humedad relativa y la temperatura de la sala son muy estables, en torno al $50 \%$ y $18^{\circ} \mathrm{C}$ respectivamente, y pueden considerarse adecuadas para la exposición de la alfombra. No se prevén equipos correctores de estos parámetros ni puesta en marcha del sistema de calefacción por hilo radiante, aunque se controlan en todo momento en función del número de visitantes y de los periodos de apertura.

\section{Niveles de iluminación}

Es posible incrementar el nivel de iluminación sobre la superficie de las piezas textiles (hasta el máximo permitido de 50 luxes) introduciendo pequeños proyectores halógenos en luminarias de pie, con potenciómetros que permitan regular la intensidad luminosa sobre la alfombra si fuera necesario.

\section{Protección antipolvo}

Es necesaria una barrera física contra el polvo durante los periodos en que la alfombra no se muestra al público. El dispositivo propuesto consiste en un "store" de grandes dimensiones, dispuesto en horizontal sobre la alfombra, que se extiende y recoge manualmente. En el vestíbulo alto se colocan alfombrillas que retienen la suciedad y el polvo aportado por los visitantes.

\section{Protección contra incendios}

No se han previsto nuevas instalaciones de protección contra incendios.
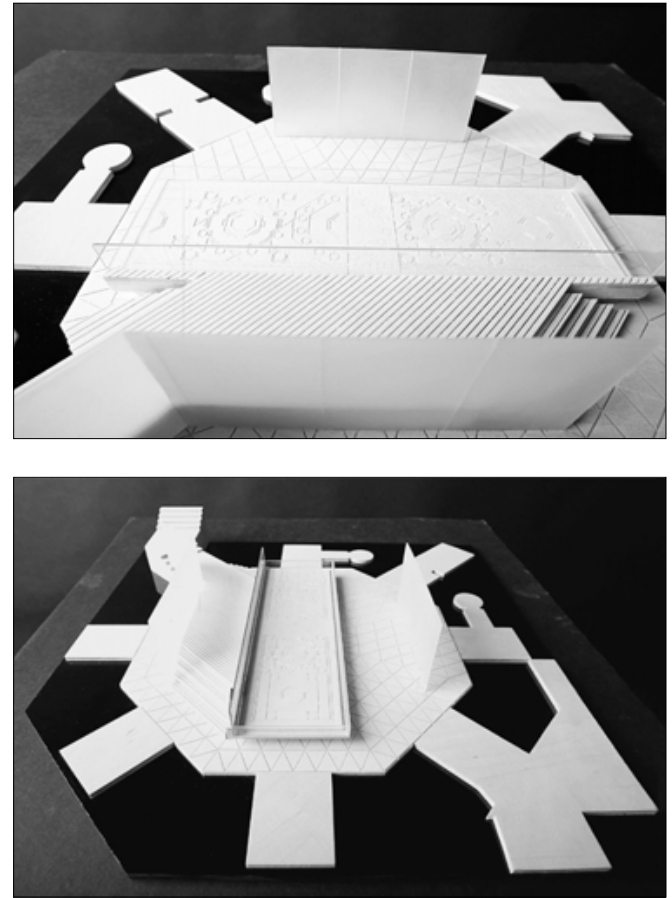

\section{Seguridad}

Son suficientes los sistemas de seguridad existentes en el Palacio y la vigilancia humana asociada al Museo de la Alhambra. No se contemplan, por tanto, otras instalaciones o equipos.

\section{Materiales y acabados}

Estructura: metálica atornillada de perfiles tubulares laminados en frío. Se dispone simplemente apoyada en el suelo sobre "sinenblock" dimensionados para la carga prevista.

Tarima: duelas de madera de roble machihembrada sobre tablero aglomerado.

Base de la alfombra: sobre el tablero aglomerado se colocan sucesivamente melinex de 125 micras, muletón y tela ocre de algodón 100\%.

Carpintería: madera de roble maciza machihembrada sobre rastreles de pino tea.

Pasamanos: de madera de roble sobre soportes de acero inoxidable pulido de $10 \mathrm{~mm}$ de espesor y vidrios laminados de seguridad $6+6 \mathrm{~mm}$.

Sistema de protección antipolvo: tejido de algodón $100 \%$.
7, 8. Maqueta del soporte de la alfombra, sobre la planta de la cripta

\section{Ficha técnica}

\section{Coordinación:}

Esther Cruces Blanco y Lorenzo Pérez del Campo

Estudio histórico-estilístico:

Cristina Partearroyo y Gabriel Ferreras Romero, Historiadores del Arte

Análisis de fibras:

Lourdes Martín García, Química

Estudio biológico:

Marta Sameño Puerto, Bióloga

Restauración:

Araceli Montero Moreno y Carmen Ángel Gómez, Restauradoras
Proyecto museográfico:

Antonio Tejedor Cabrera, Arquitecto director

Mercedes Linares Gómez del Pulgar, Arquitecta colaboradora

Raniero Baglioni, Asesor en Conservación Preventiva

Victor Baztán Cascales, Arquitecto Técnico

Silvia Pérez, Conservadoro

Fotografías: Eugenio Fernández Ruiz

Infografías: Salvador Muñoz Muñoz

Maqueta: Jacinto Gómez Piris

Montaje: Grupo Entorno 